\title{
Context Aware Fuel Monitoring System for Cellular Sites
}

\author{
*Mohammad Asif Khan, Ahmad Waqas, Qamar Uddin Khand, Sajid Khan \\ *Department of Electrical Engineering \\ Department of Computer Science \\ Sukkur IBA University \\ Airport Road, Sukkur-65200, Pakistan
}

\begin{abstract}
The past decade has been very productive for cellular operators of Pakistan, as their subscribers have grown exponentially with increase in revenue. After this wave of rising, the operators have now reached to saturation level, with the highest teledensity of all time. These Cellular Networks consist of Cell sites, which need electrical power to run. Because of electrical power shortage in Pakistan, the power needs of cell site are fulfilled by the use of electrical power generators which are installed on each site. These generators run on fossil fuel, a large amount of which is being theft from sites. This has very negative impact on Network availability and Operator's operational expenditure. To cope with this major issue of fuel theft, an embedded system is being designed and tested. This paper highlights this issue of the telecom sector and discusses the design and results of the proposed system. This system would reduce the cell site operational cost and will increase its availability in the service area.
\end{abstract}

Keywords-Fuel theft; fuel sensor; fuel management; remote monitoring

\section{INTRODUCTION}

Pakistan telecom sector has passed peak era and has entered into a position where they have started saturation in terms of subscriber penetration and now cellular operators have started optimization of their resources to reduce operational expenditure (OPEX). Operators consume most of their OPEX on the operation of their basic network entity called Base Transceiver Station (BTS). Thousands of BTS are installed by cellular operators throughout the country in the shape of BTS towers. There is temperature sensitive equipment in those BTS sites. Numbers of air-conditions are installed at the site for maintaining required temperature of that temperature sensitive equipment. The operation of these BTS towers requires heavy electrical power, which is being supplied to sites from National Electrical Grid.

Pakistan is suffering from severe Electrical shortage for past fifteen years. Load shedding from National Grid creates trouble for continuous functioning of BTS sites. In big cities of Pakistan there is scheduled electrical power shutdown from Grid for 8 to 10 hours and in small cities, towns 12 to 18 hours are being observed [1]. This large scale regular power shutdown has very negative impact on revenue, availability, operation, and maintenance of cellular networks.

To cope with a shortage of electrical power, Cellular Operators use electrical power generator as a secondary source of power for cell sites. Operators are spending a handsome amount of money for fuelling these generators. The system that is used by cellular companies for fuel filling and monitoring is manual. Because of this manual fuel system, a large amount of fuel is being theft from the site by either site guard or filler of fuel [2]. In the current manual filling system, it is very hard for Operator to identify who has performed the fuel theft.

To cope with this major issue of the telecom sector, a system is designed and discussed in this paper called the Context-Aware Fuel Monitoring System. This intelligent system updates the site engineer about different levels of the fuel and any abnormal activity if occur at the fuel tank of BTS. This context-aware system updates the site engineer through a text message that what type of anomaly has occurred with the fuel tank. This system informs the site engineer about levels of fuel, such as, what is current level of fuel, at which time of the day the generator is filled with fuel, how much amount of fuel is filled, how much liters it has consumed while running.

The main purpose behind this system is, it will report fuel theft to site engineer, also it will maintain fuel log of the site for budgeting, operation, and maintenance. By using this system, the site engineer will have information about the fuel status, and record of the log, also the system will monitor fuelling continuously for reporting any anomaly. The prototype of the system is being developed and deployed at the test site, results were gathered to test different fuel theft conditions and remote monitoring. It has been found that this system greatly reduces the fuel theft and OPEX of the Network also it increases Network availability.

This research paper is divided into seven sections. Section 2 is about the related work carried out on such issues by different researchers. Section 3 of the paper is about the electrical power setup at cellular sites. Section 4 explains the problem statement of research, whereas Section 5 discusses the design, implementation, and benefits of the system. Section 6 is used to show the results of the system in form of graphs, whereas Section 7 is a conclusion and future work of the system.

\section{RELATED WORK}

The researchers have done good work to cope with the issue of fuel theft, done at various places like cell sites, vehicles, stations, etc. In this regard Kunal Dhandel et al., have done a survey on fuel level measurement techniques used at 
various places [4]. This work represents only a survey with no idea of implementation. R Surendra et al. have done work to remotely access the cell site, and ON/OFF the generators [5], the difference between this work and the proposed system is it also cope with fuel theft where the referenced work only remotely access site generator. Ghenga et al. have worked on the development of a mechanical sensor to accurately measure the fuel level and report it back to the remote mobile phone and aplicom [6], this work has only developed fuel sensor to be used for measuring fuel level.

The research is also going on fuel theft issue in another place instead of cell sites. Riny Sulityowti et al. have worked on the remote monitoring of fuel tank by the use of the android application, for that purpose they have used Bluetooth and GSM technology [7]. Nandini Hiremath et al. have been working to detect fuel theft in a tank used anywhere, they have used ARM7 micro controller with fuel sensor to report the theft or any leak in the tank [8]. Deo Ashwini et al. worked on the computer based monitoring of fuel tank and its reporting on the web with the help of web API [9]. Alwyn Hoffman et al. have worked to identify different issue relating to fuel used in logistics [10]. Most of these systems are not coping with all kind of fuel theft also these designs don't look scalable in terms of other features which can be incorporated in the proposed system in future.

There has been a significant amount of work on cellular sites monitoring and its patents are filed. Bejiman Stump has worked on the monitoring of cellular sites power and the discharge of the battery. They are checking different sites parameter to check the feasible conditions for battery discharge, in another case, they will run the power generator [11]. Philippe Gagnon et al. have worked on the monitoring of battery backup power remotely. This work is only working on the monitoring of battery bank and evaluating the other parameters of remote site those will impact the backup time [12].

\section{EleCtrical Power at CEllular Site}

The cellular sites provide service coverage to the subscribers using different equipment which are being installed there. At the Cellular site, there is two major equipment which consumes power; cooling systems and telco equipment. If the power of cell site is shut down then the result is no availability in its coverage area. Availability of cell site has remained the key concern of cellular operator due to its direct impact on revenue. Therefore, continuous supply of power to a cell site is very important for any cellular operator.

Keeping in view the importance of electrical power at the cell site, telecom operators provide redundant electrical supply to the site for keeping it up all time. Normally in Asia Pacific region, the electrical power supply from national grid varies from $12 \mathrm{KVA}$ to $40 \mathrm{KVA}$ [3]. The electrical connectivity at any cell site is shown in Fig. 1, where the main supply comes from national grid in AC current form and goes to Automatic Transfer Switches (ATS). Similarly, backup power is also supplied from Generator set, which runs on the fuel, present in the fuel of tank attached with it. Generator's electrical power supply also goes to ATS system. The function of ATS is a switch to the available power source. In ATS, if all supplies are up then, normally the primary power supply is set from the national electrical grid. In case the Grid supply goes off, then ATS switches to generator supply. Most of the telecom equipment operates on DC power, therefore rectifier is placed between equipment and ATS supply.

The third electrical power backup is battery bank. Batteries are charged and used when both AC supplies go off. These batteries also help in the switching between Grid supply to Generator supply and vice versa. Most of the under developed countries like Pakistan faces severe shortage of Electrical power at national power grid, and as result half of the time.

Electrical power is shut down by the government for load balancing. To cope with shortage of electrical power from national grid, cellular sites availability highly depends on generators electrical power, which is running on fuel.

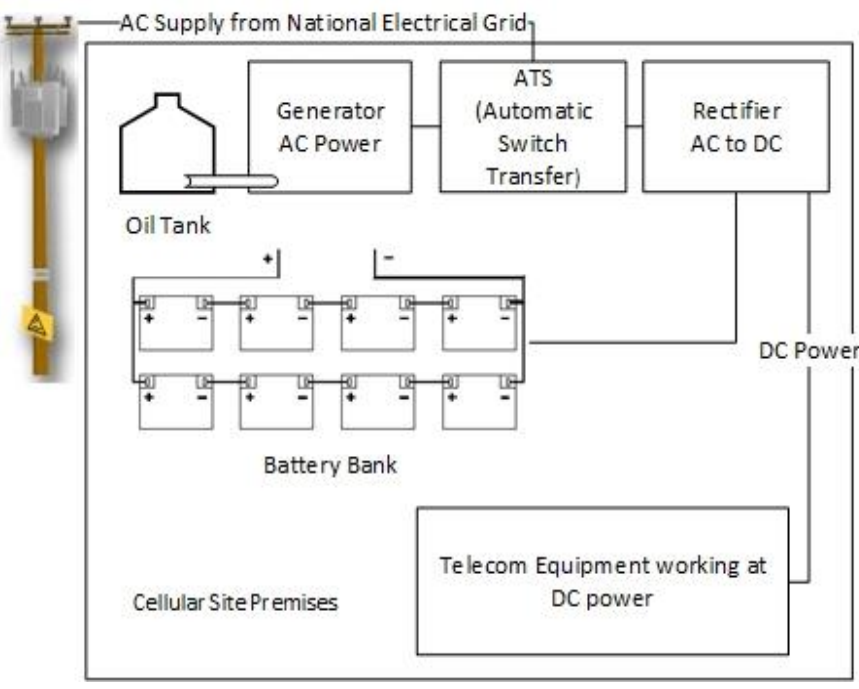

Fig. 1. Electrical power supply at cellular site.

\section{Fuel TheFt AT CELlUlar Sites}

The cellular sites' availability highly depends on the running of generators, in case of supply from national grid goes off. Generators work on the fuel i.e. diesel, therefore, each cellular site contains a fuel tank attached to a generator. In case of grid supply goes off then the generator is the best hope for site availability, but if fuel is finished, then the last line of defense for the site is battery backup. The battery bank runs for short time, and as result, sites go offline if power from a generator or national grid is OFF for longer period.

The cellular operators heavily invest on fueling of sites. Most of the time they filled the site in advance to avoid any scenario in which fuel is finished, and filling team reached after the site goes offline. But due to bad law and order condition in under developed countries like Pakistan, fuel is theft from cellular sites and in such case when grid supply also goes off then generator doesn't work due to unavailability of the fuel tank. In some part of the countries like Pakistan, almost half of the fuel is theft from sites. A survey was done to estimate fuel consumption and theft ratio. At 500 cell sites in peak seasons of May, June, July and August, when National Grid supply less electricity to sites, the cellular operators consume approximately 250,000 litres of diesel. The report 
from Operators show almost $25 \%$ to $50 \%$ of fuel is theft from sites. Let's suppose there is $25 \%$ theft over $250 \mathrm{k}$ litre of diesel, and cost of diesel/liter is 0.7 USD, then the theft amount is:

$$
\begin{aligned}
\text { Estimated Theft Cost }= & 0.25 * 250000 * 0.7 \\
& =43,750 \text { USD }
\end{aligned}
$$

The estimated theft cost is a big figure, such financial loss cannot be ignored by Operators. This fuel theft is mainly done by two parties: first the site guard, and second the filler who fill less fuel in the tank. Operators have tried their level best to use different security teams and penalties over filler but the problem still remains headache for operators. The filler and guard both deny for fuel theft and put allegations on each other in case of any theft. There should be a system which could identify those who have done fuel theft. If such information is provided then fuel theft can be reduced remarkably. This issue needs to be addressed because of its high financial impact over the cellular Operators' OPEX.

\section{COnTEXT Aware Fuel Monitoring System}

The fuel theft has a disastrous impact on the different things related to the cell site. It has a high impact over its availability also sensitive electronics equipment mostly malfunction due to power failures and per site fuel cost. There is indeed a need to address this important issue of fuel theft.

To address such important issue of fuel theft at cellular sites, a Context Aware Fuel Monitoring System is being designed. This is a microcontroller based system, through which site engineer can remotely log into site and can check the fuel status of fuel tank also it can start and stop generator remotely, this system will also report any anomaly (fuel theft) occurred during filling of fuel tank, or at any other instance of time by some other person like site guard.

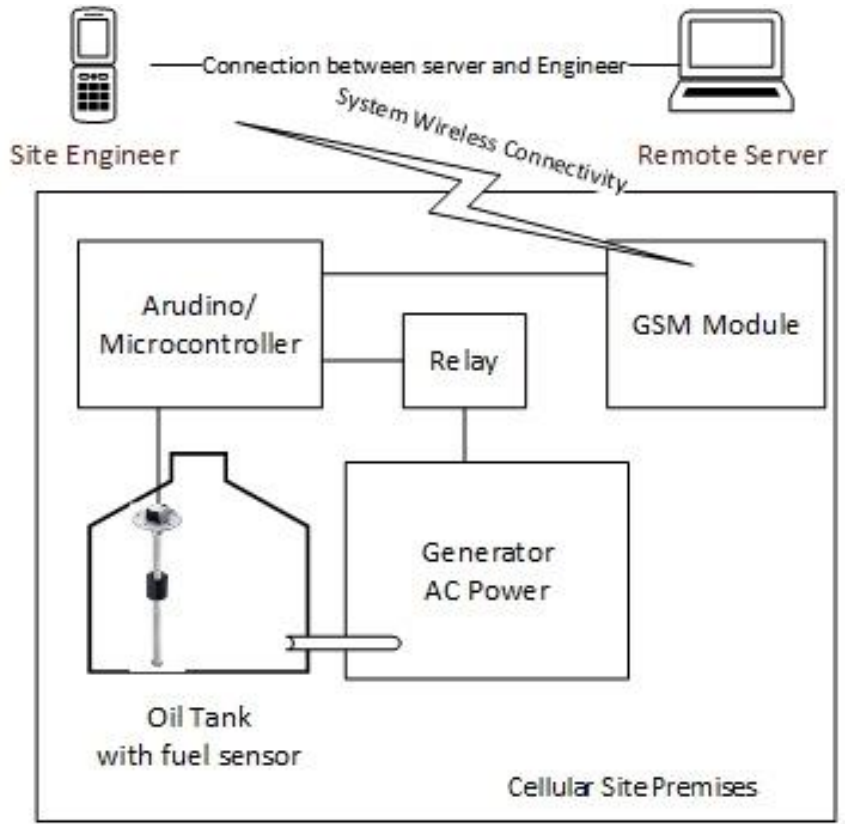

Fig. 2. System connectivity.

The system works with the single microcontroller installed at each cellular site. This microcontroller works by periodically checking fuel level of the tank using fuel sensor dipped into the tank. The fuel sensor report fuel level to the micro controller after every minute, which further reports this information to remote computer server using GSM/cellular communication module. The fuel level information is logged in a database on remote computer server which keeps the data for any future usage or audit. If there is any fuel theft either by guard or filler, it is being reported to site engineer and server by microcontroller from the site. The start and stop of the generator can be done using a relay, which takes instructions from the microcontroller. The site engineer can also remotely start and stop generator from his cell phone or computer server. The connectivity of different parts of the system is shown in Fig. 2.

The prototype which is built for the proposed system is being made with the help of Arduino Mega 2560 and Ultrasonic sensor is being used as fuel sensor, also capacitive fuel sensor can be used with the existing system. Relays are being used to start/stop the ignition of the generator. The communication from the site with engineer and server is made possible using GSM module SIM900 which can communicate over GSM as well as DCS band. Microsoft Access is used as a database for logging fuel data over a long span of time.

\section{A. Fuel Theft Detection}

The fuel theft is done in various ways by filler and guard or any other person on site. The system applies all possible ways of fuel theft. The flow chart in Fig. 3 shows how fuel theft is detected when the system is online.

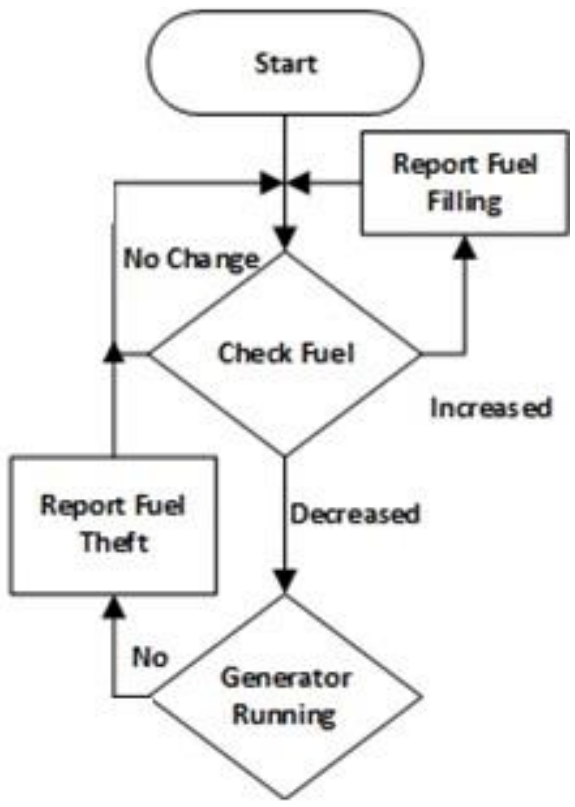

Fig. 3. Flow of fuel theft detection.

The system starts and fuel is level is detected by the sensor after each minute. If there is fuel increase then that means filler has done fueling on site and filling is reported to the server, when filling stops. In this way, the accurate filling is logged in the system. Hence, there is no chance for filler to not fill required fuel level. In case if there is a decrease in fuel level and the generator is also not running, it means fuel theft has 
occurred and is reported to server and site engineer. There is also the possibility to decrease in fuel level when the generator is also running, in such case, the fuel consumption rate will be high as compared to normal consumption of generator, as result fuel theft is also reported. During fuel level check, if there is no change in fuel level then the system re-checks fuel level after a set period and no fuel theft is reported. In this way, fuel theft is detected, as shown in flow chart of Fig. 3.

\section{B. Benefits of System}

This system has high commercial viability as described in section 3 . The system can avoid fuel theft and can save large OPEX of the cellular operator. But there are other benefits of this system. The system will reduce the malfunctioning of sensitive electronic equipment, which mostly malfunctions due to electrical shutdown. There is another benefit of an increase in site availability, which is one of major benefit from the proposed system, as with proper fueling there is less chance of site down. This system also reduces the security cost, which companies mostly spend on fuel theft investigation. This system will also improve the mobility of filling teams in case if fuel level reaches any threshold value and team reach site before the site goes down. The fuel audits will be easier and accurate with such system deployment.

\section{RESUlTS OF THE SYSTEM}

The prototype of the Context Aware Fuel Monitoring System was deployed on a running generator of 12KVA for more than five days. The system working was monitored and readings were taken successfully.

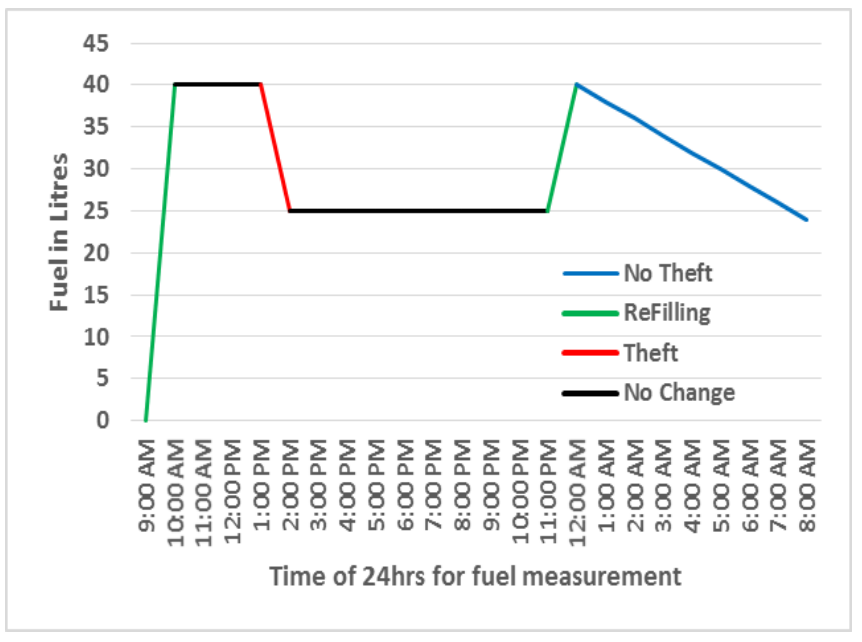

Fig. 4. Fuel theft detection with proposed system.

The system successfully detected the fuel theft, which was intentionally and randomly done in various ways. The system reported and logged various activities of fuel filling, running of generator and fuel theft.

The system at the site reported fuel level to the server after every minute. In Fig. 4 the graph shows the reading of the 3 rd day. The red line show theft detection when generators were running but fuel theft was done to avoid abrupt changes in fuel level. The graph show generator was running from 1:00 pm to 4:00 pm, but fuel consumption was very high, instead of standard 6 liters (with a margin of error), the consumption is 15 liters. Hence fuel theft was reported to server and site engineer. The red line is where fuel was theft. The black line shows no change in fuel level, means neither fuel is theft nor generator is running. The blue line appeared when the generator is running and fuel is consumed according to standard values as shown between 11:00 pm to 4:00 am.

Fig. 5 shows the results taken on the 5th day of testing when filling was done also fuel was theft with an abrupt change in fuel level, which is a very common way of fuel theft. At 09:00 am generator had a filling with 40 liters of fuel which was reported and shown with the green line. The theft occurred when someone suddenly took 15 liters of fuel from tank and generator was not running. This was reported as theft and shown with a red line. Again, filling of 15 liters was at 11:00 pm. The blue line show generator running and no theft was done, as consumption rate is matching with standard values.

All the other hardware and software parameters of the system were tested and found good during the period of testing. All the messages were properly logged on the server, and anomalies reported to server and site engineer.

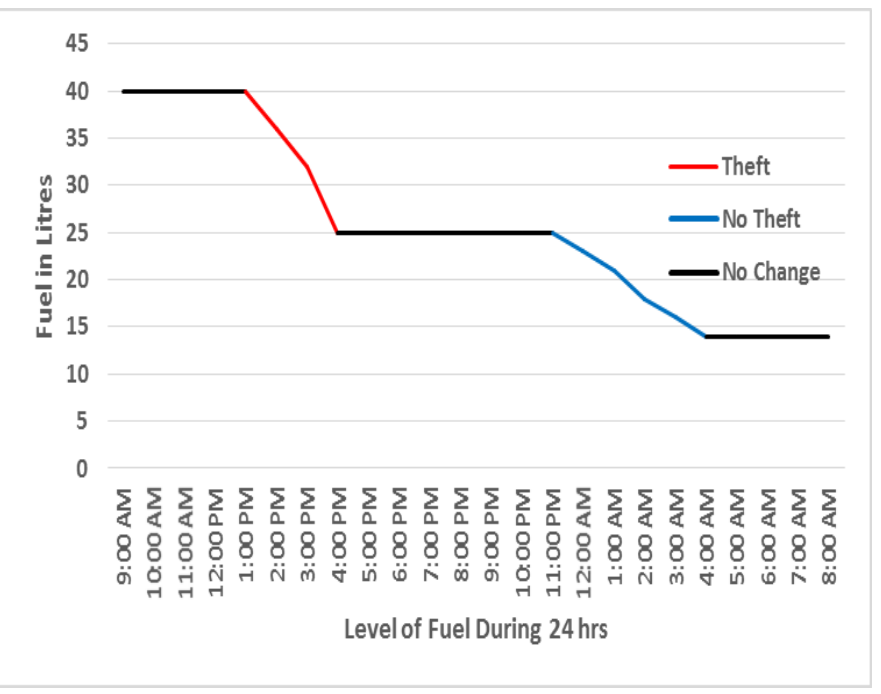

Fig. 5. Common way of fuel theft detection.

\section{CONCLUSION AND FUTURE WORK}

This paper discussed the design, implementation, and result of Context Aware Fuel Monitoring System which coped with the issue of fuel theft occurred at Cellular Sites and a large portion of Operator's revenue is lost. The proposed system was tested and results shows, all possible ways of fuel theft were detected, reported and logged for any future usage like an audit. This system has high commercial viability and will be deployed in industry. This system can also be used in other places where fuel theft is reported.

This system has very good directions in future. The research team would work and include other modules in a system which can report the electrical values (voltage, load, battery charge, fluctuation of power, etc.). There will be an android application for this system which can be used for a client (Engineer's Phone) and server (GUI access) activities. 


\section{REFERENCES}

[1] Rashid Aziz and Munawar Baseer Ahmad, "Pakistan's Power Crisis The Way Forward", United States Institute of Peace: Special Report, 375,pp 2-3, June 2015.

[2] Karen Hampton, "Ringing The Changes", Energy Storage Journal, Nov 2013 Issue.

[3] Wissam Balshe, "Power system considerations for cell tower applications", Technical information from Cummins Power Generation, Power topic \#9019, 2011

[4] Kunal Dhande1, Sarang R. "Fuel Level Measurement Techniques: A Systematic Survey", International Journal of Research in Advent Technology, Vol.2, No.4, April 2014 E-ISSN: 2321-9637.

[5] R.Surendra, B.Karunaiah, Murali Mohan, "Power Management Of Cell Sites", International Journal of Computer Technology and Applications ,Vol 3 (1), pp 5-8.

[6] Gbenga Daniel Obikoya, "Design, Construction, and Implementation of a Remote Fuel-level Monitoring System", EURASIP Journal on Wireless Communications and Networking,,December 2014.

[7] Riny Sulityowati , Bayu Bhahtra Kurnia Rafik, "Prototype Design of a
Realtime Monitoring System of a Fuel Tank at a Gas Station Using an Android-Based Mobile Application", Proceedings of Second International Conference on Electrical Systems, Technology and Information, 2015

[8] Nandini Hiremath, et al., "Smart Fuel Theft Detection using Microcontroller ARM7", International Journal of Engineering Research \& Technology. Volume. 4 - Issue. 09, September - 2015

[9] Deo Ashwini et al. , "Wsn Based Fuel Level Detection and Dispensary Monitoring System for Moving Vehicles", Journal of Emerging Technologies and Innovative Research., Volume 3, Issue 4 April 2016

[10] Alwyn J. Hoffman et al. , "An Investigation into the Economics of Fuel Management in the Freight Logistics Industry", 17th International Conference on Intelligent Transportation Systems (ITSC)., October, 2014, China

[11] Benjamin Stump, "Hybrid power management system and method for umanned remote cell sites", Westtell Inch, Patent issued Aug, 2014

[12] Philippe Gagnon, Denis Pomerleau, Roger Paradis, "Back-up power system and monitoring system therefore", Avestor Limited Partnership, Patent issued May 